\title{
Some aspects of nasal carriage of staphylococci
}

\author{
W. C. NOBle, ${ }^{1}$ R. E. O. WILliams, ${ }^{1}$ M. PATRicia JeVONS, \\ AND R. A. SHOOTER \\ From the Cross-Infection Reference Laboratory, Public Health Laboratory Service, \\ Colindale, and Department of Bacteriology, St. Bartholomew's Hospital, London
}

SYNOPSIS The nasal carrier status of 3,736 patients was determined throughout their stay in hospital. The carrier rate on admission, which was highest in patients under 20 years of age, did not appear to vary with season.

The carriage of strains resistant to penicillin increased with the patients' stay in hospital from $13.8 \%$ on admission to $20.5 \%$ on discharge, and the acquisition of these strains was enhanced by the administration of antibiotics.

Patients discharged from hospital carrying strains of staphylococci acquired in hospital lost them more readily than patients discharged carrying the strain which they had carried on admission, $31 \%$ of those discharged carrying strains resistant to penicillin and tetracycline being readmitted carrying these strains compared with $69 \%$ of those discharged carrying strains sensitive to these antibiotics.

During investigations of staphylococcal sepsis at St. Bartholomew's Hospital the patients admitted to one medical and three surgical wards were examined for nasal carriage of staphylococci on admission and thereafter at weekly intervals (Shooter, Girling, Matthias, and Williams, 1960; Williams, Noble, Jevons, Lidwell, Shooter, White, Thom, and Taylor, 1962). This extensive material, which was obtained over a period of four years, seemed to offer a chance of filling some of the gaps in our knowledge of the factors relating to staphylococcal nasal carriage, and this paper presents the results of analyses in terms of age, length of stay in hospital, antibiotic treatment, and previous admission to hospital.

\section{METHODS}

Nasal swabs were taken from the anterior nares using cotton-tipped swabs which were inoculated on to serum agar plates containing $0.01 \%$ phenolphthalein phosphate (Barber and Kuper, 1951). Phosphatase-positive colonies were tested for coagulase and coagulase-positive strains were tested for resistance to antibiotics (penicillin, tetracycline, streptomycin, chloramphenicol, and erythromycin) and were phage typed at the Staphylococcus Reference Laboratory, Colindale. Unless the presence of more than one strain of staphylococcus was suspected, only one colony from each nasal swab was tested for antibiotic sensitivity and phage type.

'Present address: Wright-Fleming Institute, St. Mary's Hospital Medical School, Paddington, London, W.2.
Throughout this paper the word 'staphylococcus' is used to mean the coagulase-positive Staphylococcus aureus and the term 'carrier' is used for anyone who yielded Staphylococcus aureus from a nasal swab. A patient was said to have 'acquired' a staphylococcus if he was a non-carrier on admission and became a carrier subsequently; or if he was a carrier but could be shown by phage typing of the staphylococci to have changed the strain he carried during his stay in hospital. Obvious intermittent carriers were not regarded as 'acquiring' a new strain each time the strain reappeared in the nose. The group of patients regarded as 'non-carriers' on admission to the wards may well have included intermittent carriers from whom we did not isolate a staphylococcus and were consequently regarded as having acquired the staphylococcus while in hospital.

The term 'sepsis' is used to denote any clinically manifest infective condition; 100 of the 206 cases of sepsis were cases of post-operative wound infection and 73 were of chest infections, the remainder being of minor sepsis such as boils.

Altogether the records for 3,736 male patients, some of whom were admitted on more than one occasion to give a total of 4,335 admissions, have been collected. Not all have been included in each analysis, however, since complete records were not available for all patients, owing to the extended nature of the survey.

\section{RESULTS}

RELATION OF NASAL CARRIAGE ON ADMISSION TO AGE On admission to the wards $40.5 \%$ of the patients carried staphylococci in the anterior nares. The total 
TABLE I

NASAL CARRIAGE OF STAPHYLOCOCCI IN RELATION TO AGE OF THE PATIENT ON ADMISSION

Age of patient on admission (yr.)

$\begin{array}{lllllllll}5-10 & 11-20 & 21-30 & 31-40 & 41-50 & 51-60 & 61-70 & 71-80 & 81-100\end{array}$

No. of patients

Percentage nasal carriers

$\begin{array}{rrrrrrrrr}40^{1} & 185 & 266 & 313 & 485 & 686 & 636 & 281 & 33 \\ 70 & 60 & 41 & 42 \cdot 8 & 39 & 39 \cdot 1 & 36 \cdot 5 & 37 \cdot 2 & 12\end{array}$

Percentage patients carrying strains

S/PT

$\mathbf{R} / \mathbf{P}, \mathbf{S} / \mathbf{T}$

R/PT

$\begin{array}{ccrcccccc}32 \cdot 5 & 41 \cdot 4 & 28 \cdot 5 & 27 & 27 & 28 \cdot 4 & 25 & 23 & 6 \\ 32 \cdot 5 & 18 & 10 \cdot 3 & 13 & 10 \cdot 7 & 7 \cdot 5 & 9 & 10 \cdot 3 & 6 \\ 5 & 0.6 & 2 \cdot 2 & 2 \cdot 8 & 1 \cdot 3 & 3 \cdot 2 & 2 \cdot 5 & 3 \cdot 9 & 0\end{array}$

$\mathbf{S} / \mathbf{P T}=$ sensitive to penicillin and tetracycline

$\mathbf{R} / \mathbf{P}, \mathbf{S} / \mathbf{T}=$ strains resistant to penicillin but sensitive to tetracycline

$\mathbf{R} / \mathbf{P T}=$ resistant to penicillin and tetracycline

There were no patients under 5 years of age. One patient was aged 5 years and the rest evenly distributed over the range 6 to 10 years.

Only four patients were over 90 years of age. None was 100 or over.

staphylococcal carrier rate was considerably higher in the patients under 20 years of age than in the older patients (Table I).

Strains resistant to penicillin and tetracycline were carried by $2.5 \%$ of the patients on admission; there was no significant difference in the rate at different ages. On average about $10 \%$ of patients carried penicillin-resistant strains on admission, the youngest patients having the highest rates. There was no great difference in the rates over the years 1956 to 1961.

SEASONAL VARIATION IN NASAL CARRIAGE Meteorological data, derived from Air Ministry data for central London, were plotted against the mean monthly carrier rate on admission for a total of 2,646 patients admitted between December 1957 and January 1961. There was no clear correlation of carrier rate with season, nor was this rate correlated with the mean monthly temperature or relative humidity.

Likewise there was no correlation between season and the frequency with which patients in the ward acquired staphylococci (computed as the number of acquisitions per 1,000 patient-days' exposure).

CARRIAGE DURING STAY IN HOSPITAL AND EFFECT OF ANTIBIOTICS Previous work (e.g., Williams et al., 1962) has shown that patients acquire staphylococci during their stay in hospital. However, this increase in carrier rate is influenced not only by length of stay in hospital but also by antibiotic treatment and the development of a septic lesion and these three factors are inter-related. An attempt to disentangle them is presented in Tables II, III, and IV, which are basedy on patients undergoing operations from whom twe or more nasal swabs were received during their hospital stay.

Those patients who developed sepsis acquire nasal staphylococci more often than those who did not develop sepsis, as did those patients who receive antibiotics, whether or not they developed sepsis (Table II).

In Tables III and IV patients who developed sepsi are omitted. There was a steady increase in acquisio tion rate with length of stay in hospital both for those $\overrightarrow{\vec{E}}$ who received and those who did not receive anti 3 biotics (Table III).

Patients who were not nasal carriers of staphylo cocci on admission to hospital acquired nasal staphy lococci more often than those admitted carrying staphylococci, regardless of antibiotic therapy although in both groups the incidence was highei among the patients who had had antibiotics.

CARRIAGE OF STAPHYLOCOCCI ON DISCHARGE The total carrier rate at the last routine swabbing befor

TABLE II

EFFECT OF ANTIBIOTICS ON CHANGE IN CARRIER STATUS IN PATIENTS WITH AND WITHOUT SEPSIS Length of Time in Hospital

\begin{tabular}{ll} 
No Antibiotics Given & \\
\hline No. of Patients & $\begin{array}{l}\% \text { Acquiring Nasal } \\
\text { Staphylococcus }\end{array}$
\end{tabular}

Patients developing sepsis ${ }^{1}$
$\leqslant 12$ days

$>12$ days

Patients not developing sepsis

$\leqslant 12$ days

$>12$ days

$\begin{array}{rr}12 & 16 \cdot 7 \\ 67 & 47 \cdot 8 \\ & \\ 287 & 9 \cdot 8 \\ 412 & 25 \cdot 2\end{array}$

\begin{tabular}{ll} 
Antibiotics Given \\
\hline No. of Patients & $\begin{array}{c}\% \text { Acquiring Nasal } \\
\text { Staphylococcus }\end{array}$
\end{tabular}

'Sepsis' includes wounds in which there was visible pus and other clinically recognizable infective complications, usually in the chest, due any organism. 
TABLE III

EFFECT OF LENGTH OF TIME IN HOSPITAL IN RELATION TO CHANGE IN CARRIER STATUS AND ADMINISTRATION OF ANTIBIOTICS IN PATIENTS NOT DEVELOPING SEPSIS

Length of Time in Hospital (days)

\begin{tabular}{|c|c|c|c|c|}
\hline \multirow[t]{2}{*}{ Length of Time in Hospital (days) } & \multicolumn{2}{|c|}{ No Antibiotics Given } & \multicolumn{2}{|l|}{ Antibiotics Given } \\
\hline & No. of Patients & $\begin{array}{l}\text { \% Acquiring Nasal } \\
\text { Staphylococcus }\end{array}$ & No. of Patients & $\begin{array}{l}\text { \% Acquiring Nasal } \\
\text { Staphylococcus }\end{array}$ \\
\hline $\begin{array}{r}<12 \\
12-20 \\
21-30 \\
31-40 \\
>41\end{array}$ & $\begin{array}{r}287 \\
299 \\
74 \\
27 \\
12\end{array}$ & $\begin{array}{r}9 \cdot 8 \\
20 \cdot 7 \\
33 \cdot 7 \\
44 \cdot 4 \\
41 \cdot 7\end{array}$ & $\begin{array}{l}62 \\
96 \\
93 \\
30 \\
38\end{array}$ & $\begin{array}{l}16 \cdot 1 \\
22.9 \\
36 \cdot 6 \\
46.7 \\
73 \cdot 7\end{array}$ \\
\hline
\end{tabular}

Antibiotics Given

TABLE IV

EFFECT OF ANTIBIOTICS ON CHANGE IN CARRIER STATUS OF PATIENTS EITHER CARRIERS OR NON-CARRIERS ON ADMISSION TO THE WARDS ${ }^{1}$

No Antibiotics Given

No. of Patients $\quad \%$ Acquiring Nasal Staphylococcus

Carriers on admission

Non-carriers on admission

141

271
Antibiotics Given

No. of Patients $\quad \%$ Acquiring Nasal Staphylococcus

${ }^{1}$ All these patients were in hospital for more than 12 days and none of them suffered sepsis

the patients left the ward was $43 \%$ (of 4,002 patient discharges). Twenty-two per cent of patients were discharged carrying a penicillin-sensitive strain, $14.5 \%$ a strain resistant to penicillin only, and $6 \%$ a strain resistant to penicillin and tetracycline. These rates may be compared with $40.5 \%$ for carriers on admission, with $27 \%$ of the patients carrying sensitive strains, $10.4 \%$ carrying strains resistant to penicillin only, and $2.5 \%$ resistant to penicillin and tetracycline.

In one of the wards neomycin nasal cream and hexachlorophene soap were used for the control of an outbreak of staphylococcal cross-infection. The period of this treatment has been omitted from the rest of the analysis, but during the treatment period the percentage of patients discharged from the wards as non-carriers was higher than for the other periods (70\% of 484 patients). Sixteen per cent were discharged carrying a penicillin-sensitive strain, $9 \%$ a penicillin-resistant strain and $4.5 \%$ a strain resistant to penicillin and tetracycline.

CARRIER STATUS ON READMISSION TO THE WARDS During the course of the investigation, 374 patients were readmitted to the wards on one or more occasions giving a total of 599 readmissions.

From Table V it can be seen that $62 \%$ of the 246 patients who had been discharged as nasal carriers were readmitted carrying the same strain; $14 \%$ (34) carried a new strain as determined by phage-typing and antibiotic resistance. In 25 of the 34 patients the new strain and the original strain belonged to different phage groups, thus indicating a complete change of strain rather than a minor change in the pattern of lysis of the initial strain.

Patients who acquired nasal staphylococci in the hospital lost them more readily after discharge than those who were discharged carrying the strain that

TABLE V

CARRIAGE OF STAPHYLOCOCCI ON READMISSION

Carrier Status on Discharge $\%$ Patients Readmitted

\begin{tabular}{lll}
\hline Carrying Same Strain As Non-carriers Carrying New Strain & $\begin{array}{l}\text { Total No. of Patients } \\
\text { Observed }\end{array}$
\end{tabular}

Discharged carrying strains
S/PT
R/P, S/T
R/PT

Total carriers

Non-carriers

$68 \cdot 7$
62
31

$61 \cdot 7$

16
$28 \cdot 2$
45

$24 \cdot 4$

$84 \cdot 1$

$\begin{array}{cr}15 \cdot 3 & 125 \\ 9 \cdot 8 & 92 \\ 24 & 29 \\ 13.9 & 246 \\ 15.9 & 353\end{array}$

${ }^{1} R / P, S / T$ indicates a strain resistant to penicillin but sensitive to tetracycline

The difference between the three groups of carriers is significant between the $1 \%$ and $0 \cdot 1 \%$ levels. 
TABLE VI

CARRIER STATE ON READMISSION IN PATIENTS DISCHARGED CARRYING THE STAPHYLOCOCCUS CARRIED ON FIRST ADMISSION OR CARRYING A HOSPITAL-ACQUIRED STAPHYLOCOCCUS

Days from Discharge Patient Discharged Carrying to Readmission

\begin{tabular}{cl} 
& \\
\hline $1-50$ & $\begin{array}{l}\text { 'Own' staphylococcus } \\
\text { Hospital-acquired staphylococcus }\end{array}$ \\
$51-150$ & $\begin{array}{l}\text { 'Own' staphylococcus } \\
\text { Hospital-acquired staphylococcus }\end{array}$ \\
$>151$ & $\begin{array}{l}\text { 'Own' staphylococcus } \\
\text { Hospital-acquired staphylococcus }\end{array}$
\end{tabular}

they had carried on admission (Table VI); not only did more of those who had been discharged carrying a hospital-acquired staphylococcus return as noncarriers but more returned carrying other strains.

Eighty-seven of the patients were admitted three or more times during the course of the investigation. Twenty-eight ( $32 \%)$ never carried staphylococci, 18 $(21 \%)$ carried the same strain throughout, $11(13 \%)$ carried different strains, and $30(35 \%)$ showed intermittent carriage.

Seventy-three patients lost the strain carried on the first admission during their stay in hospital, becoming either non-carriers or carrying another strain. Thirtyeight $(52 \%)$ of these patients carried the original strain again at the second admission.

\section{DISCUSSION}

Many studies have been carried out on the change in nasal carrier status with time in newborn and young children but there have been few such studies of adolescents and adults. Miller, Galbraith, and Green (1962), in a survey of staphylococcal carriers in patients attending their general practitioners, found that the carrier rate was highest in the age group 5-14 years and had settled to the adult level in the 15-24 age group. The carrier rate in our series was also highest in the patients under 20 years of age but the numbers are not large enough to permit further breakdown.
$\%$ Patients Readmitted

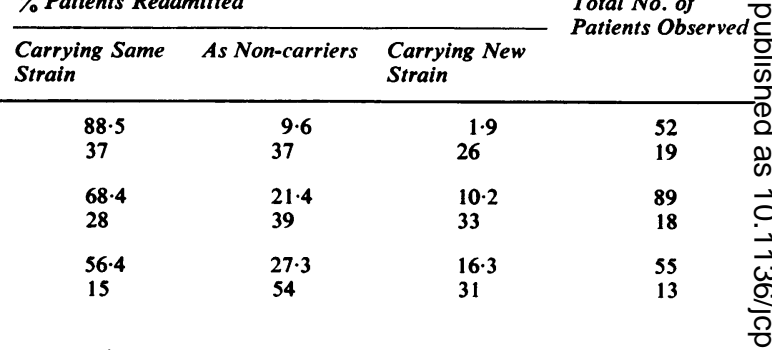

Since the carrier rate for staphylococci is fairly similar for a number of different countries and climates (Williams, 1963), it is perhaps not surprising that, in common with Miles, Williams, and Clayton? Cooper (1944), we failed to find any relation between? the carrier rate and season in Great Britain.

Previous work has indicated that the administra s tion of an antibiotic tends to eliminate the antibiotic sensitive flora from the nose and allow recolonization with an antibiotic-resistant flora; the emergence of pre-existing antibiotic-resistant bacteria from the original flora seems in comparison to be rare (Barber: 1947; Knight, White, and Martin, 1958). This is confirmed in our series. Of 1,300 patients who were carriers on admission to hospital, 1,092 received n\& antibiotics; $164(15 \%)$ of these acquired a newo staphylococcus. Of the 208 patients receiving anti biotics, $108(53 \%)$ acquired a new staphylococcus as determined by phage-typing (Table VII). No clear evidence of a change in antibiotic sensitivity unac? companied by a change in phage type was seen:From studies on the airborne staphylococci in the wards to which these patients were admitted it seem $\$$ likely that between 40 and $50 \%$ of the staphylococc $\bar{x}$. inhaled by the patients were resistant to penicillirs and so it is not surprising that many of the patients acquired penicillin-resistant staphylococci in the nose.

Goslings and Büchli (1958) in a follow-up study found that patients discharged from hospital carryin

TABLE VII

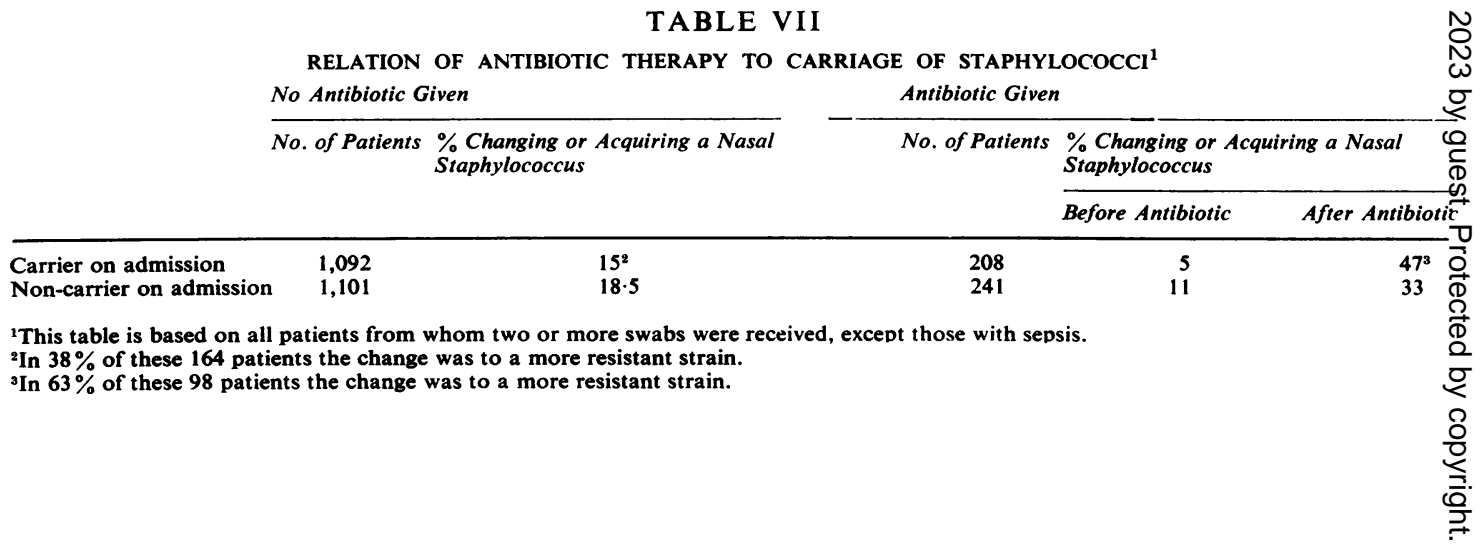


penicillin-resistant staphylococci lost them and became non-carriers more readily than patients discharged carrying penicillin-sensitive strains. Miller, McDonald, Jevons, and Williams (1962) in a study of Royal Air Force personnel found that penicillinresistant staphylococci were more readily acquired and more rapidly lost than sensitive strains and these observations have been amply confirmed by our own investigations.

It thus seems that the selective advantage of antibiotic resistance which enables the strain to make a success of colonization in the hospital environment is in some way disadvantageous when the selective agent is removed. This, however, is not true for all strains, for Johnson, Rountree, Smith, Stanley, and Anderson (1960) have shown that hospital strains of staphylococci of phage type $80 / 81$ have spread extensively outside hospital in Australia.

In our studies about half of the patients who appeared to have lost the strain of staphylococcus which they carried on admission to the hospital were subsequently readmitted carrying their original strain. Jarvis and Wigley (1961) reported a similar recolonization of the nose in nurses treated with Neobacrin and Soframycin. This recolonization could have arisen from carriage of the staphylococcus on another body site or from members of a patient's family. In other unpublished studies (Simpson and
Noble) we have found, however, that about $65 \%$ of hospital out-patients with staphylococci in the anterior nares also carry staphylococci on either the inferior or middle turbinates or in the post-nasal space.

We are grateful to our clinical colleagues in the Hospital who have allowed us to examine their patients and to the Medical Research Council and the Treasurer and Governors of St. Bartholomew's Hospital for grants in support of the work.

\section{REFERENCES}

Barber, Mary (1947). Brit. med. J., $2,863$.

, and Kuper, S. W. A. (1951). J. Path. Bact., 63, 65.

Goslings, W. R. O., and Büchli, K. (1958). Arch. intern. Med., 102, 691.

Jarvis, Audrey W., and Wigley, R. D. (1961). Lancet, 2, 1168.

Johnson, A., Rountree, Phyllis M., Smith, Katherine, Stanley, N. F., and Anderson, K. (1960). Spec. Rep. Ser. No. 10, Nat. Hlth med. Res. Coun. (Canberra).

Knight, V., White, A. C., and Martin, M. P. (1958). Ann. intern. Med., $49,536$.

Miles, A. A., Williams, R. E. O., and Clayton-Cooper, B. (1944). J. Path. Bact., 56, 513.

Miller, D. L., Galbraith, N. S., and Green, Susan M. (1962). Brit. J. prev. soc. Med., 16, 203.

- McDonald, J. C., Jevons, M. Patricia, and Williams, R. E. O. (1962). J. Hyg. (Lond.), 60, 451.

Shooter, R. A., Girling, J. A., Matthias, J. Q., and Williams, R. E. O. (1960). Brit. med. J., 1, 1923.

Williams, R. E. O. (1963). Bact. Rev., 27, 56.

$\longrightarrow$, Noble, W. C., Jevons, M. Patricia, Lidwell, O. M., Shooter, R. A., White, R. G., Thom, B. T., and Taylor, G. W. (1962). Brit. med. J., 2, 275. 